\title{
A Review on Cross-Layer Design Approach in WSN by Different Techniques
}

\author{
Sultana Parween*, Syed Zeeshan Hussain
}

Department of Computer Science, Jamia Millia Islamia, New Delhi, 110025, India

\author{
A R T I C L E IN F O \\ Article history: \\ Received: 12 June, 2020 \\ Accepted: 07 August, 2020 \\ Online: 28 August, 2020
}

Keywords:

Cross-Layer Design (CLD)

Cross-layer Framework (CLF)

Data management Framework

Energy efficiency

Quality of Service (QoS)

TinyCubus

Wireless Sensor Network (WSN)

\begin{abstract}
A B S T R A C T
Wireless Sensor Networks (WSN) include a large number of sensor nodes that are connected to each other with the limitations in energy sources, battery life, memory, mobility and computational capacity. Since the traditional layered architecture was appropriate only for the wired network. It works within a strict boundary that leads to more energy usage as well as more communication traffic. It also impacts on the overall network lifespan and performance of the system. Energy efficiency and network lifespan are the primary concern of WSN due to the fact that each node in the network operates with extremely limited energy. Recent studies have shown that the Open System Interconnection (OSI) model cannot meet the demands of the wireless sensor network.

To overcome such limitations, the cross-layer design has been introduced. It allows direct interactions between protocol at non-adjacent layers. In this paper, we present different types of cross-layer design techniques in Wireless Sensor Network (WSN) and discusses several cross-layer proposals given by researchers. At the end, the paper highlights some challenges faced in implementing CLD in Wireless Sensor Networks.
\end{abstract}

\section{Introduction}

Nowadays WSN has evolved into one of the "on-demand" wireless systems that can be generally used in many fields like environmental monitoring, habitat monitoring, military surveillance, smart spaces and medical systems, and so on [1]. The key purpose of the WSN is the detection, collection, computation and transfer of the data to the sink node.

Normally, sensor nodes are powered by batteries, that are difficult to replace or recharge. Power limitation is to be considered one of the most significant factors while designing a sensor network. However, as interference, fading and noise are common in wireless network communication. To overcome the error caused by the above reason during the data transmission, sensor nodes need to use more energy [2]. There are many techniques and protocols used by several researchers to reduce energy consumption. There are still many open challenges to developing an appropriate energy-saving technique for sensor nodes in WSN. Increasing the lifespan of nodes in the wireless sensor network is important as the usage of this network is unreliable for much of the time and it is difficult to repair the batteries or faulty nodes. Thus, several researchers have carried out various solutions for an energyefficient model in different situations. The traditional layered

"Corresponding Author: Sultana Parween, New Delhi, India | Email: sultana.tech@gmail.com architecture might not be suitable and efficient in the wireless environment due to the basic features of wireless communication [3]. In this point of view, cross-layer design for cross-layer optimization being an optimal approach, that is not only to improve but also optimize the overall network performance. Different cross-layer interaction and optimization techniques used by the WSN designer and developers to provide QoS in WSNs. The major contribution of this paper is consequently that of supplying researchers with a summarized comparison of existing CLD approaches by the different techniques in WSN. As Jurdak defines it "Cross-layer design techniques with respect to the reference layered model are the design of protocols, architectures, or algorithms, that not only exploit but also offer a set of inter-layer interaction which is a superset of the standard interfaces provided by the overall reference layered architecture" [4].

The focus of this paper is to explore the cross-layer optimization techniques in the context of wireless sensor networks. The remaining portion of the paper is organized in the following sections: Section 1 describes the brief overview of CLD and its objective and significance. It also explains the need for cross-layer design in WSN. Section 2 presents the research gap. Section 3 briefs the cross-layer design framework in WSN. Section 4 describes the cross-layer design implementation method. Section 5 covers different cross-layer design techniques. Section 6 briefs 
the categorization of recent cross-layer design by a different technique. The challenges of cross-layer design in wireless sensor networks are discussed in section 7. Finally, Section 8 gives the conclusion of this paper.

\subsection{A brief explanation of Cross-Layer Design}

The OSI layered architecture comprised of basically seven layers and these layering structures brings many benefits: it breaks the complex task of networking into separate parts simplifies design; it makes protocols easier to optimize, manage, and maintain; the lower layers can be changed without affecting the upper layers [5]. Although the traditional layering structure is beneficial for wired networks because it provides modularity, transparency, standardization, and abstract functionality. It means that this structure is not suitable for a wireless network. The main purpose behind this is that, there are strict boundaries in the OSI model, all the protocol is proposed for a single layer and each layer cannot communicate directly with the non-adjacent layer. And this characteristic is opposite to energy limitation, node mobility, and the dynamic nature of wireless sensor networks [6]. An approach that could exchange information across many layers is needed to solve this problem. Therefore, the cross-layer technique has affected increased attention. The basic idea of a cross-layer is to use the close interaction between different layers for improving the performance of the entire network. For many domains, this technique has been widely used.

\subsection{The objective of Cross-Layer Design in WSN}

The major goals that needs to be considered while designing a cross layer architecture are mentioned below.

Table 1: Objective of CLD

\begin{tabular}{|l|l|}
\hline Goals & Explanation \\
\hline $\begin{array}{l}\text { 1.Network lifetime } \\
\text { maximization }\end{array}$ & $\begin{array}{l}\text { It is significant in the context of enhancing } \\
\text { the flawless operation of battery- } \\
\text { constrained WSNs. }\end{array}$ \\
\hline $\begin{array}{l}\text { 2.Energy-efficient } \\
\text { routing }\end{array}$ & $\begin{array}{l}\text { The CLD is responsible for creating a } \\
\text { perfect routing algorithm to calculate the } \\
\text { best routing path, which could not only } \\
\text { consume minimum power but also maintain } \\
\text { the network connectivity. }\end{array}$ \\
\hline $\begin{array}{l}\text { 3.Reliable event } \\
\text { detection and transfer }\end{array}$ & $\begin{array}{l}\text { The main request for an event-based sensor } \\
\text { network is to detect an event and transport } \\
\text { the data accurately. }\end{array}$ \\
\hline $\begin{array}{l}\text { 4.Optimization among } \\
\text { multiple, conflicting } \\
\text { objectives }\end{array}$ & $\begin{array}{l}\text { To find the optimal scheme, which } \\
\text { concerning the conflicting goals, to } \\
\text { accomplish the best performance of the } \\
\text { sensor network }\end{array}$ \\
\hline $\begin{array}{l}\text { 5.Bringing flexibility } \\
\text { into the application- } \\
\text { specific design of } \\
\text { WSNs }\end{array}$ & $\begin{array}{l}\text { The CLD should be flexible enough to } \\
\text { satisfy the dynamic requirement of different } \\
\text { application. }\end{array}$ \\
\hline
\end{tabular}

\subsection{Why do we need a Cross-Layer Design?}

The traditional layered method avoids communication among nonadjacent layers in the protocol stack, which limits its use in wireless sensor networks (WSN) [7]. CLD method helps in breaking the traditional waterfall idea that was considered in traditional network protocols. CLD doesn't destroy the traditional layered structure of the networks [8]. It additionally presents the inter-layer communication between non-adjacent layers. With the help of CLD, the internal status and parameters of every layer can be revealed to the different layers ensuing in the removal of redundancy. CLD also helps in figuring out the behaviour of different layers by way of retrieving and receiving the facts from them [9]. CLD helps in increasing the functionality of the wireless network, quality of service, mobility, and security in sharing information amongst all layers. To get the maximum energy consumption in WSNs, a cross-layer can be useful.

\subsection{Significance of Cross-Layer Design}

The motivating points that trigger to apply the cross-layer design approach were numbered as follows.

- It improves network efficiency and satisfy the quality of service requirements of various applications [10].

- It increases network performance and optimizes network throughput [11].

- It is used to enhance the performance of sensor nodes.

- It allows communication among various non-adjacent layers and the exchange of information amongst them.

- It helps to reduce the transfer load through exchanging information across different layers.

- It maintains the features and functions related to the layers, but to allow for coordination, communication, and optimization of protocols across various layers.

- It is an appropriate technology for overcoming some of the current TCP/IP stack limitations, particularly for wireless networks.

\subsection{Assessment among Conventional layered approach and CLD approach}

After a review of existing work, we find Comparisons between CLD Approach and the Conventional layered approach [11].

Table 2: Comparison table of Conventional Layered approach and CLD approach

\begin{tabular}{|l|l|}
\hline CLD Approach & Conventional Layered Approach \\
\hline $\begin{array}{l}\text { CLD approach minimizes the } \\
\text { communication traffic efficiently. }\end{array}$ & $\begin{array}{l}\text { Communication traffic is more in a } \\
\text { conventional layered approach. }\end{array}$ \\
\hline Nodes ingest less energy. & $\begin{array}{l}\text { Energy consumption by the nodes is } \\
\text { more likely to be in this approach. }\end{array}$ \\
\hline $\begin{array}{l}\text { Appropriate for both wired as well as } \\
\text { wireless networks. }\end{array}$ & $\begin{array}{l}\text { More appropriate for a wired } \\
\text { network. }\end{array}$ \\
\hline $\begin{array}{l}\text { We can interact with one layer to } \\
\text { any other non-adjacent layer in a } \\
\text { cross-layered approach. }\end{array}$ & $\begin{array}{l}\text { We cannot interact with one layer to } \\
\text { the other non-adjacent layer in the } \\
\text { conventional layered approach. }\end{array}$ \\
\hline
\end{tabular}

\section{Research Gap}

After a review of several works the gaps in existing work are mentioned below:- 


\section{S. Parween et al. / Advances in Science, Technology and Engineering Systems Journal Vol. 5, No. 4, 741-754 (2020)}

- It is not clear how when and where the cross-layer proposals should be implemented in CLD.

- It is hard to review and redesign because changes in subsystem may cause changes in other parts of the system [12].

- There is a lack of standardization in cross-layer design that leads to many problems. The network performance should be decreased due to this reason.

- Parameters that are similar across all layers need to be identified.

\section{Cross-Layer Design Framework}

\subsection{TinyCubus}

The architecture of TinyCubus provides a new conventional model that can satisfy many different application specifications. It is flexible and adaptive by nature and applied to the top of TinyOS with the help of the necessary programming language [13]. It has many components like a Data management framework (DMF), a Cross-Layer Framework (CLF), and a Configuration Engine (CE). Tiny DMF as stated in [14]. It offers a set of data management as well as the system components that are selected dynamically. It is also responsible for selecting the proper implementation based on system information. The cube of fig 1 named 'Cubus' integrates all the optimization parameters like energy, communication latency, etc.

CLF helps in cross-layer information sharing \& management. E.g. if some of the application and the link-layer component requires information regarding the actual network neighbourhood, then one of its components in the framework collected that information and provide it to all others. A tiny cross-layer framework is not sufficient to give proper parameterization for most of the cases. This problem is solved by the Tiny Configuration Engine. It enables reliable and efficient code delivery, by taking into consideration sensor topology and its assigned functionality [15]. Figure 1 shows the key components in TinyCubus.

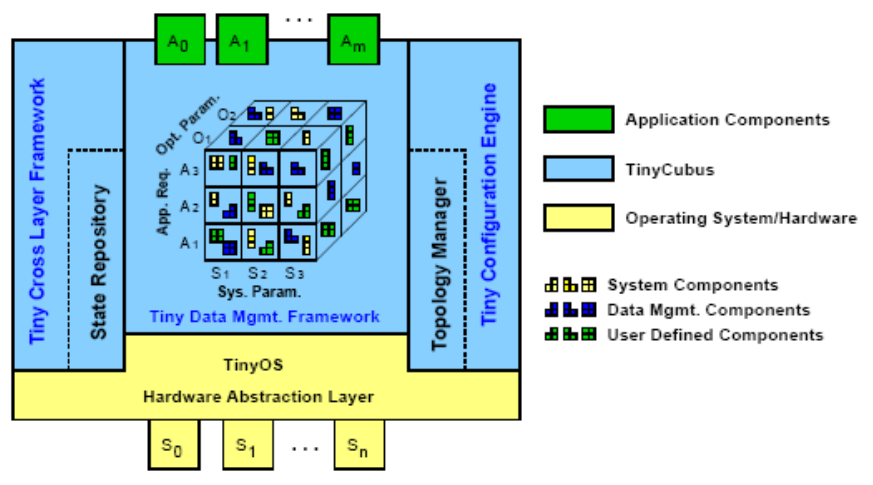

Figure 1: The architecture of TinyCubus [15]

\subsection{DMA-CLD Framework}

DMA-CLD refers to the Dynamic Multi-Attribute Cross-Layer Design framework [16]. In this framework, various objectives are met. The main purpose of DMA-CLD is to enable cross-layer connections with wireless ad hoc networks \& WSN to achieve various as well as probably overlapping goals (networking, nodal, single layer, and cross-layer). DMA-CLD framework recognizes a set of routes chosen to maximize the network performance according to given parameters like "residual battery," "reliable packet transmission", etc. as input [17]. Figure 2 showing the main idea for DMA-CLD.

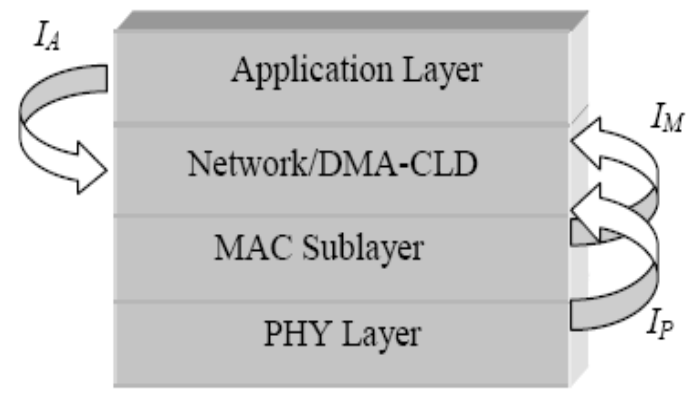

Figure 2: The architecture of DMA-CLD[16]

\subsection{Optimization Agent-Based Framework}

The main aim of this framework is to emphasize wireless channel \& physical layer properties. It is an extended version of DMA_CLD [17]. It utilizes an optimizing agent to transmit the significant changes in the physical layer as well as a wireless channel to other layers. The basic interactions among different layers are intra-layer interaction or inter-layer interaction. The directions of interaction were maybe bottom-up or top-down. Figure 3 shows the OA based framework.

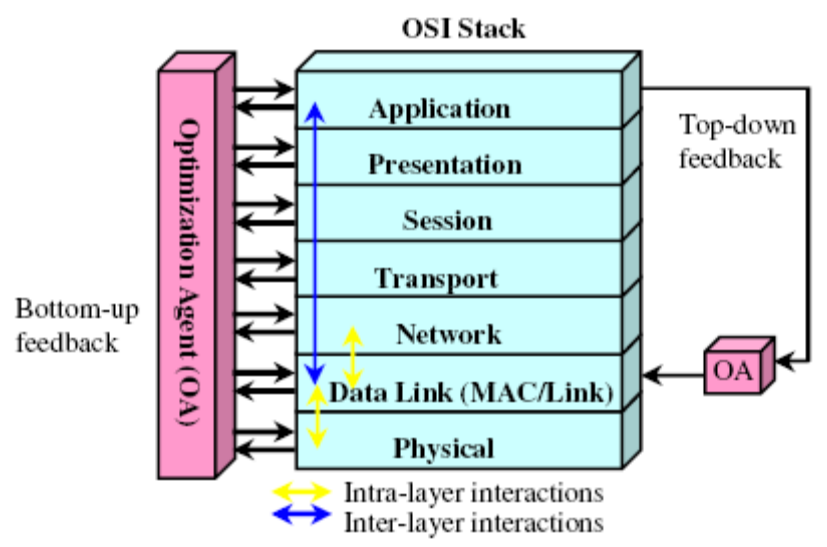

Figure 3: The architecture of the OA based framework[17]

\subsection{Horizontal Framework}

This framework comprises of the basic entities: cross-layer management entity, application, and protocol stack as shown in figure 4. The main reason for using the Horizontal model rather than a vertical model framework is to optimize the protocol stack height and to reduce resource use [17]. The CLM provides a shared data structure and needs to take care of different features of the sensor network, such as topology control and energy savings whereas APS is accountable for the data transmission of only application-specific. It also includes several extra features for the application and other layers that can be used in the protocol stack. The main concept for using this framework is just to streamline the 
protocol stack and isolate such activities like CLM entity modules, thereby enabling application programming easier [14].

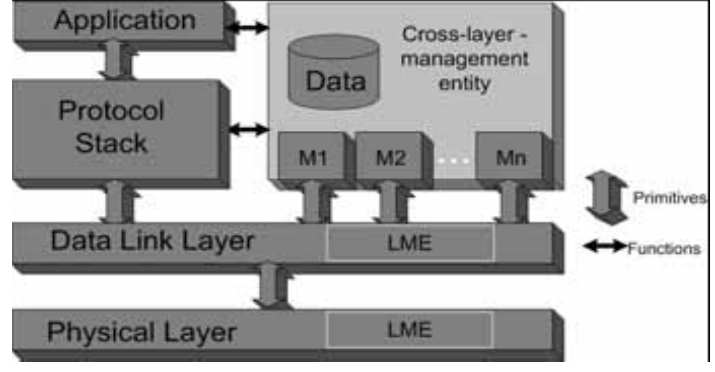

Figure 4: The architecture of Horizontal framework[14]

\subsection{XLM Framework}

XLM is a unified cross-layer framework that was created to achieve reliable and effective communication in WSN with minimal energy costs. It incorporates the protocol layer's most essential feature into a single cross-layer system that is used to provide all the requirements for effective communication [14]. XLM's architecture is built upon an initiative concept that gives full authority to each and every sensor node to determine, when and how to take part in the process of communication [18].

\section{Cross-Layer Design Implementation Method}

After an analysis of existing work, three Implementation strategies for the cross-layer design approach are identified:

\subsection{Straightforward communication between layers}

In straightforward communication among the layers, allow the variables at one layer are accessible to all the other layers during runtime. Straightforward communication among layers is the easiest way of exchange information among layers in runtime. It allows direct interaction among layers [19]. It is shown in Figure 5:

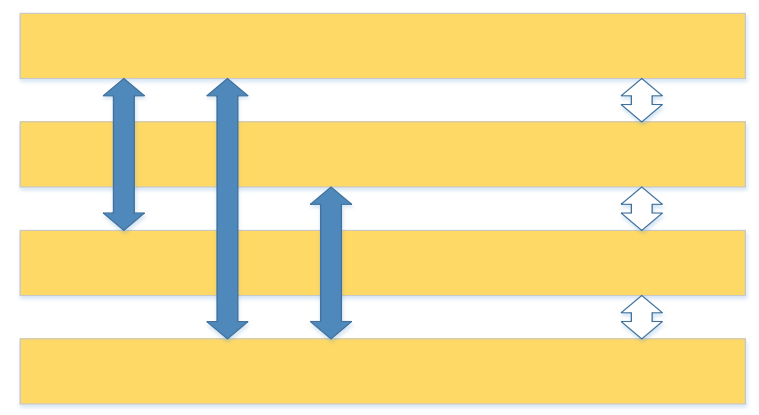

Figure 5: straight forward communication between different layers[19]

\subsection{A Common database between the layers}

As shown in Figure 6, there is a common database among the layers, which can be shared by all the layers. Just like a new layer, it provides a resource-share service to each and every layer [20]. The common database method is ideal for common resource sharing. The common database can connect to different layers at once by an optimization program [21].

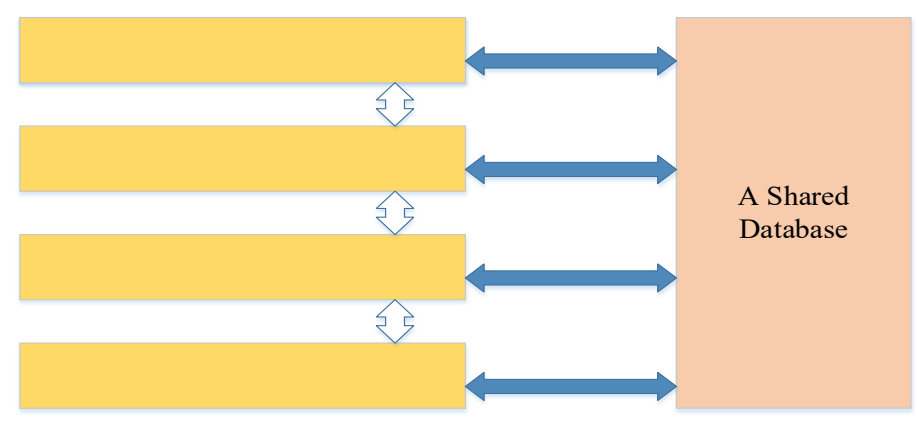

Figure 6: A Common Database across layers [19]

\subsection{Completely new abstractions}

Each layer can communicate from each and every other layer in a completely new abstraction. A completely new abstraction approach allows strong communications between different layers and it provides more flexibility during runtime [21]. It is shown in Figure 7.

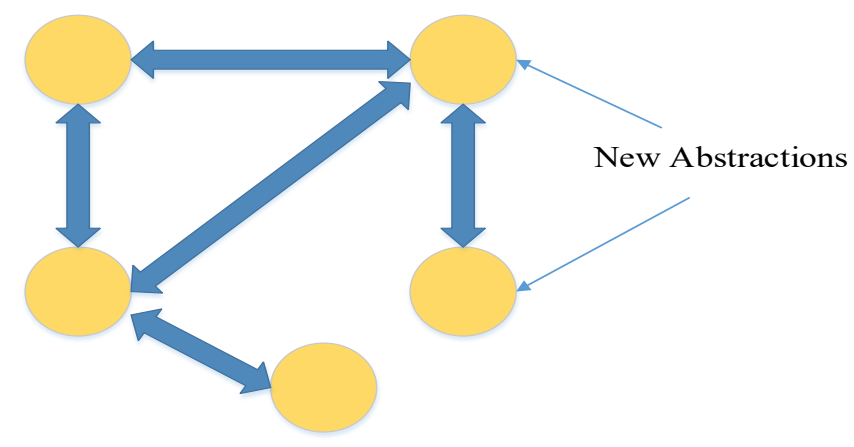

Figure 7: Completely new abstractions [21]

\section{Cross-Layer Design Optimization Techniques}

Each layer contributes to different functionalities in the protocol stack of WSNs. Crossing these layers can accomplish performance gain in different scenarios. The most common of these performance enhancements are discussed in this section. Energy efficiency is a broad category as the nature of WSN is resourceconstrained with respect to energy [22]. The key focus of each similar contribution is the energy preservation of such networks. Other areas such as QoS and communication, reliability, error correction, network resource management along with security are also discussed. Cross-Layer approach is one of the most significant emerging technique that communicates across layers for upgrading the complete performance of the network, increases energy efficiency, reduces power consumption, and deliver real-time communications for achieving quality of service (QoS) [23].

\subsection{Energy Efficiency}

An energy-efficient usage is one of the main and critical constraints in the WSN. For prolonging the lifespan of the network, it is essential to save energy at every node. The major challenges of WSN are to design an energy-efficient algorithm that significantly reduces the usage of energy during the transmission 


\section{S. Parween et al. / Advances in Science, Technology and Engineering Systems Journal Vol. 5, No. 4, 741-754 (2020)}

of data. Many researchers are working to improve energy efficiency through a different technique [24].

Cross-layer methods proved that it is better than layered equivalent and it offers much better optimization outcomes. Though, the overall performance of WSNs is greatly enhanced by layer cooperation in cross-layer based systems [25].

The following are several other works that make a significant contribution to energy efficiency by using cross-layer design approaches.

The authors in [7] proposed different modulation techniques to extend network lifetime and use the energy of WSNs in the best possible way. They suggested that when the sensor nodes within a diameter of 35 to 40 meters be run on BPSK or 8PSK modulation technique. When the sensor nodes and their $\mathrm{CH}$ (cluster head) and border nodes above 40 meters be run on 16 PSK or 4 QAM modulation technique.

The authors in [26] presented a very popular technique to solve energy consumption issues i.e. LEACH (Low-energy adaptive clustering hierarchy). It is appropriate for large-scale networks and problems of the wireless channel are identified throughout the packet forwarding. They are taking into consideration the residual power and SNR rate. LEACH has significantly improved with multi-shop communications by determining the right possible route from the source cluster head to the destination cluster head. The simulation outcome clearly indicates that it outperforms the traditional LEACH in terms of several parameters like network lifespan, power consumption \& PDR.

In a typical LEACH algorithm, it is difficult to share information among each layer, so the communication overhead increased. But the authors in [27] proposed a novel technique to improve energy efficiency and reduce overhead. The algorithm of routing for Leach-CLO(Cross-Layer Optimization )is built upon the typical Leach algorithm along with a cross-layer optimization model. The WSN should also communicate with the bottom three layers to save energy. Routes are determined by the network layer through residual energy information, thereby, reducing energy usage. The experimental findings indicate that this algorithm can balance energy usage in wireless sensing networks effectively \& efficiently in comparison to other related algorithms.

In [28], the authors proposed a cross-layer optimization technique that considers both the routing layer and the MAC layer. The routing layer balances the traffic flow through multiple paths that can enhance energy conservation. The MAC layer controls the retry limit of retransmissions for each wireless link, further energy conservation can be achieved, thus improving the network lifetime.

The authors in [29] proposed a cross-layer optimization technique that improves Dynamic Source Routing (DSR) to reduce the frequency of recomputed paths. It enables DSR to initiate route discovery when link failure is occurring. This technique can improve the DSR's routing energy efficiency.

www.astesj.com
In [30], the authors proposed an energy-aware routing technique based on a cross-layer approach for WSNs. A cross-layer routing algorithm uses the information from different layers to help the routing protocol in deciding the next hop. A fuzzy logic-based approach used to prolong the sensor node's lifetime.

The authors in [31] presented a cross-layer technique HECMAC. The technique was based on the integrated procedure of a duty cycling MAC protocol and a reconfigurable beam-steering antenna. The authors have used information from MAC and network layers to handle the scheduling process of MAC to reduce power consumption. Although the proposed technique has improved the performance but, achieving an accurate antenna adaptive approach is an extremely challenging task.

On the other hand, the author in [1] proposed an energy-efficient technique i.e. EECL (Energy-efficient cross layer) approach. The EECL approach utilizes X-MAC protocol to maintain an asynchronous duty cycle process as they consume less energy. It provides short preliminary instructions which shift to get up/sensing mode just for the routing node whereas the other nodes are in sleeping mode. Therefore, X-MAC protocol overcomes the issues of low power listening: overhearing, unnecessary preamble, and mismatch with packetizing wireless channels.

The authors in [32] suggested a new technique named CLEEP designed for the improvement of energy efficiency through WSN. It utilizes the cross-layer method by taking into consideration only three layers. Throughout the physical layer, it handles the transmission power among the nodes and periodically maintains the neighbour's table. By using the neighbour's table, each node makes a routing table in the network layer. Eventually, the MAC layer uses the information of the routing table to find the dutycycle of the node. The findings of simulation reveal that the new protocol is more energy-efficient and leads to achieving better performance enhancement.

Based on the above method, the authors in [33] suggested another technique for the improvement of energy efficiency i.e. EECP. It is a type of CLEEP protocol and used essentially to improve and optimized the performance of the network. It utilizes those data that are produced by the layers. It is mainly designed to facilitate effective data communication by reducing energy consumption. In this protocol data routes towards the node that has the highest energy rate and that is also nearest to the sink. But on the other hand, it takes into account the MAC layer information to calculate the node's service cycle and to increase the sleep' state. A comparative analysis reveals that EECP may boost system performance when compared with CLEEP.

The authors in [34] developed a hybrid technique named ATEER. They proposed a WSN adaptive threshold routing protocol for the energy-efficient cross-layer network. In this paper, the algorithm presents the initialization, deployment, selection of $\mathrm{CH}$, the formation of a cluster, and the transmission of gathered information to the base station. The simulation results show that 


\section{S. Parween et al. / Advances in Science, Technology and Engineering Systems Journal Vol. 5, No. 4, 741-754 (2020)}

ATEER has enhanced network lifetime as compared to old techniques

In [35], the authors applied a metaheuristic technique like SA (simulated annealing) for cross-layer energy-aware topology control problem. They suggested optimizing problems to reduce energy consumption through energy control, packet transfer via ECC, and topology regulation in WSNs with power-aware. SA algorithm should be useful in the evaluation of the modified topology. When they compared their results it indicates the SA provides a much better solution than the random sampling.

The authors in [36] presented an energy-efficient transmission technique named EAP-CMAC. This protocol employed physical layer network coding (PNC) that could minimize transmission time slots and achieving better performance and power efficiency than conventional network coding. Direct communication, conventional communication, and PNC-based communication are selected by the EAP-CMAC based on correct communication mode and taking into account the target queue as well as the link quality of the source-destination. However, a combined relay function and energy algorithm were measured in the context with position and residual energy node that not only increases the network lifespan but also saving power. The simulation results demonstrate that EAP-CMAC's performance in terms of network life is better than IEEE 802.11 and CoopMAC. Besides, the suggested optimal level of power allocation tends to increase the performance of EAP-CMAC by $7 \%$ particularly in comparison with the same power allocation for network lifespan.

In [37], the authors implemented a cross-layer architecture with a different timescale technique that included constraints such as congestion and power control, and processing delay. A primary aim is just to develop a cross-layer architecture that improves overall efficiency as well as reduces the overall communication latency and energy usage.

The authors in [38] presented a solution for 6LoWPAN Wireless Sensor Network to boosts the efficiency of mobility handover via different extents. Such approaches emphasize the convergence of the two separate processes i.e. Layer $2 \&$ Layer 3 handover. It provides an effective combination of these handovers to improve the overall handover performance.

In [39], the authors have proposed a framework trying to find the optimal packet size for transmission with decreased energy consumption. And based on the calculation the authors find the packet size and energy consumption are related to three parameters, that are the condition of channel, medium access and routing.

Table 3: Comparative analysis of different CLD approaches for WSN by energy efficiency

\begin{tabular}{|c|c|c|c|c|}
\hline Reference Paper & CLD approach & $\begin{array}{l}\text { Layers contributed in } \\
\text { CLD approach }\end{array}$ & Result of CLD approach & Future scope \\
\hline [1] & $\begin{array}{l}\text { Proposed CLD approach for } \\
\text { energy-efficient } \\
\text { communication i.e. EECL for } \\
\text { cloud wireless green } \\
\text { communications }\end{array}$ & $\begin{array}{l}\text { Network, MAC and } \\
\text { Physical layer }\end{array}$ & $\begin{array}{l}\text { The short preamble implemented } \\
\text { in X-MAC only with target node } \\
\text { address and minimizes delay and } \\
\text { overhearing issues. }\end{array}$ & $\begin{array}{l}\text { Future work would be to } \\
\text { implement the suggested } \\
\text { EECL approach with } \\
\text { various network } \\
\text { characteristics. }\end{array}$ \\
\hline [7] & $\begin{array}{l}\text { The CLD approach for the } \\
\text { optimization of layers and } \\
\text { framework for WSN has been } \\
\text { proposed. }\end{array}$ & $\begin{array}{l}\text { Network, DLL and } \\
\text { Physical layer }\end{array}$ & $\begin{array}{l}\text { Uniform clustering can be applied } \\
\text { to minimize interference, path } \\
\text { loss, and preserve energy. }\end{array}$ & $\begin{array}{l}\text { Future work may include } \\
\text { testing of the hardware } \\
\text { analysis and evaluating the } \\
\text { findings. }\end{array}$ \\
\hline$[26]$ & $\begin{array}{l}\text { Proposed cross-layer } \\
\text { approach for deriving } \\
\text { analytical expression of the } \\
\text { energy consumption along } \\
\text { with the small and large scale } \\
\text { channel fading. }\end{array}$ & $\begin{array}{l}\text { Physical layer, Network } \\
\text { layer }\end{array}$ & $\begin{array}{l}\text { Improving the existing cross-layer } \\
\text { clustering approach concerning } \\
\text { network lifespan and power } \\
\text { efficiency, without penalties for } \\
\text { the PDR. }\end{array}$ & $\begin{array}{l}\text { Evaluate the optimum } \\
\text { residual energy values as } \\
\text { well as the SNR thresholds } \\
\text { allowing for PDR energy } \\
\text { minimization and delay } \\
\text { constraints. }\end{array}$ \\
\hline [27] & $\begin{array}{l}\text { A ring cross-layer } \\
\text { optimization model is } \\
\text { suggested to improve energy } \\
\text { efficiency }\end{array}$ & $\begin{array}{l}\text { Network, DLL and } \\
\text { Physical layer }\end{array}$ & $\begin{array}{l}\text { LEACH cross-layer optimization } \\
\text { is used for energy saving. }\end{array}$ & \\
\hline [34] & $\begin{array}{l}\text { Energy efficient CLD } \\
\text { approach which is based on } \\
\text { adaptive threshold sensitive } \\
\text { distributed routing protocol }\end{array}$ & $\begin{array}{l}\text { Transport layer, MAC } \\
\text { layer, Physical layer }\end{array}$ & $\begin{array}{l}\text { ATEER is tested and simulated by } \\
\text { previously established routing } \\
\text { protocols. It has increased the } \\
\text { lifespan of the network in contrast } \\
\text { with the old techniques. }\end{array}$ & \\
\hline
\end{tabular}


S. Parween et al. / Advances in Science, Technology and Engineering Systems Journal Vol. 5, No. 4, 741-754 (2020)

\begin{tabular}{|c|c|c|c|c|}
\hline [35] & $\begin{array}{l}\text { Adopted Cross-layer method } \\
\text { for energy-aware optimization } \\
\text { of power control and } \\
\text { technique of topology control } \\
\text { using Simulated Annealing }\end{array}$ & $\begin{array}{l}\text { Physical, Data link, and } \\
\text { Network layer }\end{array}$ & $\begin{array}{l}\text { Simulated Annealing leads to } \\
\text { better solutions as compared to } \\
\text { Random Sampling. }\end{array}$ & $\begin{array}{l}\text { To derive conclusions on } \\
\text { energy consumption and } \\
\text { topology control } \\
\text { comparing Customized } \\
\text { Metaheuristic Probabilistic } \\
\text { to SA. }\end{array}$ \\
\hline [33] & $\begin{array}{l}\text { Proposed a novel protocol } \\
\text { named EECP for routing in } \\
\text { WSN }\end{array}$ & $\begin{array}{l}\text { Network layer, MAC } \\
\text { layer, and Physical layer }\end{array}$ & $\begin{array}{l}\text { EECP reduces power consumption } \\
\text { and increases the lifespan of the } \\
\text { wireless network }\end{array}$ & $\begin{array}{l}\text { Plan to extend the work by } \\
\text { enhancing the protocol in } \\
\text { terms of the selection of the } \\
\text { next-hop and allowing the } \\
\text { case of equal costs and } \\
\text { eliminating loops. }\end{array}$ \\
\hline [36] & $\begin{array}{l}\text { Proposed CLD approach for } \\
\text { new cooperative } \\
\text { communication protocol }\end{array}$ & $\begin{array}{l}\text { Physical and Network } \\
\text { layer }\end{array}$ & $\begin{array}{l}\text { EAP-CMAC performs better than } \\
\text { the existing protocol and improves } \\
\text { energy efficiency. }\end{array}$ & $\begin{array}{l}\text { Performance of EAP- } \\
\text { CMAC will be considered } \\
\text { in vehicular networks in } \\
\text { terms of high mobility. }\end{array}$ \\
\hline [38] & $\begin{array}{l}\text { Cross-layer mobility support } \\
\text { scheme }\end{array}$ & $\begin{array}{l}\text { Network layer and link } \\
\text { layer }\end{array}$ & $\begin{array}{l}\text { Evaluated and analyzed the } \\
\text { protocol's performance parameters } \\
\text { such as latency handover, cost of } \\
\text { handover, and packet loss rate. }\end{array}$ & - \\
\hline [39] & $\begin{array}{l}\text { CLD approach to get the } \\
\text { optimum size of data packets } \\
\text { in WSN }\end{array}$ & MAC and Physical layer & $\begin{array}{l}\text { The packet length is optimized to } \\
\text { lower energy usage per bit and } \\
\text { enhance the network lifespan. }\end{array}$ & \\
\hline [40] & $\begin{array}{l}\text { Proposed CLD for magnetic } \\
\text { induction based WUSNs }\end{array}$ & $\begin{array}{l}\text { Transport layer, Network } \\
\text { layer, MAC layer }\end{array}$ & $\begin{array}{l}\text { DEAP provides high system } \\
\text { throughput and extremely low } \\
\text { power consumption within just an } \\
\text { obligatory delay. }\end{array}$ & \\
\hline [41] & $\begin{array}{l}\text { CLD approach for energy- } \\
\text { efficient and reliable routing } \\
\text { to be achieved in WSN }\end{array}$ & $\begin{array}{l}\text { MAC, Network and PHY } \\
\text { layer }\end{array}$ & $\begin{array}{l}\text { DRPC can save more energy } \\
\text { when compared with DPC and } \\
\text { ETX-based routing. }\end{array}$ & -------------------- \\
\hline [42] & $\begin{array}{l}\text { CLD approach to improve } \\
\text { energy efficiency }\end{array}$ & $\begin{array}{l}\text { Network layer, Physical } \\
\text { layer, MAC layer }\end{array}$ & $\begin{array}{l}\text { To improve interactions in CLD, } \\
\text { the interface among the various } \\
\text { layers needs to be updated. }\end{array}$ & $\begin{array}{l}\text { Introduce the new protocol } \\
\text { for energy conservation. }\end{array}$ \\
\hline
\end{tabular}

\subsection{Quality of Service}

A CLD has now become a better way to increase Quality-ofService in WSN. Implementation of QoS techniques in WSNs is considerably challenging because WSNs were originally developed for non-real-time applications with low data-rate. WSN designers and developers, therefore, lead to various crosslayer communication and optimization techniques to provide QoS in WSNs. A few cross-layer design techniques are described in the following section.

The authors in [43] presented the cross-layer QoS techniques as delay-aware and reliability-aware techniques. They highlighted the main QoS challenges in WSNs that are related to delay and reliability-aware applications.

The authors discussed a cross-layer technique in [44] are IQOS that optimizes the quality of service factors of the sensor nodes at the bottom three layers of the wireless protocol stack because QOS factors exist in these layers. Another cross-layer technique presented in [45] is XLCP (cross-layer-communication protocol) based on QOMOS architecture. It is capable to offer soft and scalable service differentiation in QOMOS architecture.
A cross-layer approach is an important technique to optimize the QoS requirement of different types of data. In [46], the authors utilized a cross-layer design between the physical layer and MAC layers. Analyze and compare the performance of the QoS control scheme and standard scheme. The results show that the proposed scheme performed better than the standard scheme.

The authors in [47] proposed a novel cross-layer framework for QoS support in WMSNs. The objective is to maximize the capacity of the deployed network to enhance the number of video sources given that the QoS constraint of each source is also preserved. It is accomplished by implementing Wyner-Ziv lossy distributed source coding at the sensor node with a variable group of pictures (GOP) size.

\subsection{Reliable Communication}

The cross-layered framework performs better than the layered solution. Many experimental simulations show that the average transmission reliability of the cross-layered design has an improvement when compared with the layered counterpart.

Congestion is always caused by communications waste and minimization in energy efficiency. The authors in [49] presented a cross-layer approach that takes the benefit of communication 


\section{S. Parween et al. / Advances in Science, Technology and Engineering Systems Journal Vol. 5, No. 4, 741-754 (2020)}

among MAC and network layer to detect and control congestion. The MAC layer detects congestion by querying the network layer before transmitting any packet. When congestion is observed, the MAC layer begins its priority scheduling function using prioritybased packet dispatching and packet drop policy to manage congestion, thus increasing real-time transmission in WSN. A Novel congestion mitigation technique is used in [50]. This technique works well in the application, MAC, and network layer. SUIT (Sensor Fuzzy-based Image Transmission) is a new crosslayer transport protocol that provides a fuzzy logic method for estimating and mitigating the congestion efficiently. It uses two different techniques that are adapting video frame rate at the source node and new congestion mitigation technique which can adapt the quality of the image on the fly.

Table 4: Comparative analysis of different CLD approaches for WSN by QoS.

\begin{tabular}{|c|c|c|c|c|}
\hline Reference Paper & CLD approach & $\begin{array}{l}\text { Layers contributed } \\
\text { in CLD approach }\end{array}$ & Result of CLD approach & Future scope \\
\hline [43] & $\begin{array}{l}\text { CLD approach to QoS in } \\
\text { WSNs to meet the optimum } \\
\text { latency and reliability }\end{array}$ & $\begin{array}{l}\text { MAC layer and } \\
\text { Physical layer }\end{array}$ & $\begin{array}{l}\text { Qos challenges in WSN that } \\
\text { are associated to delay and } \\
\text { reliability-aware applications. }\end{array}$ & -----------------------' \\
\hline [44] & $\begin{array}{l}\text { CLD approach for IQOS } \\
\text { control scheme in WSN. }\end{array}$ & $\begin{array}{l}\text { Network, DLL and } \\
\text { Physical layer }\end{array}$ & $\begin{array}{l}\text { IQOS improve energy } \\
\text { effectiveness, quality of } \\
\text { service and system throughput } \\
\text { in WSN. }\end{array}$ & \\
\hline [45] & $\begin{array}{l}\text { CLD approach for QoSMOS } \\
\text { in WMSNs }\end{array}$ & $\begin{array}{l}\text { Network layer and } \\
\text { Data link layer }\end{array}$ & $\begin{array}{l}\text { XLCP helps to provide and } \\
\text { distinguish QoS to various } \\
\text { levels of service class. }\end{array}$ & $\begin{array}{l}\text { Evaluate the performance of } \\
\text { the current protocol in terms } \\
\text { of node mobility and loss. }\end{array}$ \\
\hline [46] & $\begin{array}{l}\text { CLD approach for QoS in } \\
\text { WBAN }\end{array}$ & $\begin{array}{l}\text { Physical layer and } \\
\text { MAC layer }\end{array}$ & $\begin{array}{l}\text { Performance Analysis and } \\
\text { optimization of the quality of } \\
\text { service (QoS) control system } \\
\text { in WBANs. }\end{array}$ & $\begin{array}{l}\text { Evaluate and analyse the } \\
\text { other error control schemes } \\
\text { and access protocols. }\end{array}$ \\
\hline [47] & $\begin{array}{l}\text { A framework for CLD in } \\
\text { support of QoS under WMNs }\end{array}$ & $\begin{array}{l}\text { Application, } \\
\text { Network, and DLL }\end{array}$ & $\begin{array}{l}\text { QoS constraint can be } \\
\text { achieved by implementing } \\
\text { Wyner-Ziv lossy distributed } \\
\text { video coding. }\end{array}$ & ----- \\
\hline [48] & $\begin{array}{l}\text { CLD approach for QoS in } \\
\text { WMSNs }\end{array}$ & $\begin{array}{l}\text { Network and MAC } \\
\text { layer }\end{array}$ & $\begin{array}{l}\text { Clustered multipath routing in } \\
\text { WMSNs as well as QoS } \\
\text { aware scheduling for various } \\
\text { traffic classes. }\end{array}$ & $\begin{array}{l}\text { Emphasis on maximizing } \\
\text { threshold values based on } \\
\text { Network specification in } \\
\text { mathematical representation } \\
\text { and Simulation. }\end{array}$ \\
\hline
\end{tabular}

Table 5: Comparative analysis of different CLD approaches for WSN by reliable communication

\begin{tabular}{|c|l|l|l|l|}
\hline Reference Paper & CLD approach & $\begin{array}{l}\text { Layers contributed in } \\
\text { CLD approach }\end{array}$ & Result of CLD approach & Future scope \\
\hline$[49]$ & $\begin{array}{l}\text { A framework of Cross- } \\
\text { Layer to improve } \\
\text { transmission reliability }\end{array}$ & $\begin{array}{l}\text { Network layer and MAC } \\
\text { layer }\end{array}$ & $\begin{array}{l}\text { Congestion detection and } \\
\text { congestion control to } \\
\text { accomplish real-time } \\
\text { transmission in WSN. }\end{array}$ & $\begin{array}{l}\text { Plans for more network } \\
\text { parameters to be tested. }\end{array}$ \\
\hline$[50]$ & $\begin{array}{l}\text { SUIT is a cross layer- } \\
\text { based image transport } \\
\text { protocol }\end{array}$ & $\begin{array}{l}\text { Application, Transport, } \\
\text { MAC and Network layer }\end{array}$ & $\begin{array}{l}\text { The fuzzy-logic method is } \\
\text { used for evaluating and } \\
\text { minimizing the congestion } \\
\text { effectively. }\end{array}$ & $\begin{array}{l}\text { Plan to apply prioritization of } \\
\text { packets based on fuzzy-logic } \\
\text { technique. }\end{array}$ \\
\hline$[51]$ & $\begin{array}{l}\text { CLD scheme to enhance } \\
\text { video quality in WMSNs }\end{array}$ & $\begin{array}{l}\text { Physical and Transport } \\
\text { layer }\end{array}$ & $\begin{array}{l}\text { Compressed sensing video } \\
\text { transmission to provide high- } \\
\text { quality video to the receiver. }\end{array}$ & $\begin{array}{l}\text { Measure the system } \\
\text { performance and complexity } \\
\text { with other video encoders and } \\
\text { channel encoding. }\end{array}$ \\
\hline$[52]$ & $\begin{array}{l}\text { Forwarding scheme based } \\
\text { on CLD for video sensor } \\
\text { network(VSN) }\end{array}$ & MAC and Network layer & $\begin{array}{l}\text { LBRF and DLBS introduce } \\
\text { significant improvement as } \\
\text { regards to the reliable data } \\
\text { delivery in VSN }\end{array}$ & $\begin{array}{l}\text { RRA method is used to } \\
\text { improve data gathering } \\
\text { performance in WMSNs. }\end{array}$ \\
\hline$[53]$ & $\begin{array}{l}\text { CLD approach for reliable } \\
\text { video transmission }\end{array}$ & $\begin{array}{l}\text { Transport, Network and } \\
\text { Physical layer }\end{array}$ & & \\
\hline
\end{tabular}




\subsection{Security}

Security is always the main concern of WSNs. The idea of cross layering has improved the efficiency of WSN communication. It also reduces modularity by the exchange of parameters between layers that enhance wireless sensor network communication capacity, reliability, and efficiency. Notwithstanding these many successes, there have been security threats in a cross-layering model.

The authors in [54] suggested a new cross-layer technique i.e. TXLM, which considers a comprehensive solution to securing a sensor-based network. This model uses the trusted method to initiate and coordinate interactions between entities in an intimidating routing process. A cross layering framework of TXLM builds on the XLM. They also introduced TruFiX, a T-XLM inspired protocol of configurable cross-layer. The security efficiency of TruFiX was compared with RBSS protocols through comprehensive simulation experiments. The results indicate that the TruFiX performs better than the RBSS-based protocols to packet delivery.

XLM security features are not strong in [54], so another authors in [55] suggested the fuzzy logic calculation method which is used to provide defence against attacks. It is mostly based on trust and used to calculate the reputation of nodes to allow safe data transmission and accurate data delivery through a cross-layer architecture. It shares interlayer information by using different parameters to reduce security attacks on WSN.

In [57], the authors have proposed a cross-layer optimization technique to secure the delivery of images through wireless channels. The desirable parameters-BER, ARQ retry limit, and transmission rate are optimized across the three layers (i.e. PHY, MAC, and APP) with respect to image distortion reduction required and energy-efficient communication.

In [58] the authors have presented an Efficient Dynamic Selective Encryption Framework (EDES) to ensure the security of multimedia traffic in WMSNs. EDES proposed three security levels and the selection depends upon the energy and QoS parameters. A cross-layer approach is used for EDES to take different parameters from the physical, MAC, and upper layers. The capacity metric is used for the evaluation to increase or decrease the level of security. The EDES is a two-step framework wherein in the first step, network performance parameters are determined by combining the QoS parameters and residual energy to capacity function CAP. This requires parameters from the MAC, network, and upper layers. The second step selects the security level based on CAP.

Table 6: Comparative analysis of different CLD approaches for WSN by Security

\begin{tabular}{|c|c|c|c|c|}
\hline Reference Paper & CLD approach & $\begin{array}{l}\text { Layers contributed } \\
\text { in CLD approach }\end{array}$ & Result of CLD approach & Future scope \\
\hline$[54]$ & $\begin{array}{l}\text { CLD framework } \\
\text { introduces TruFiX } \\
\text { mechanism }\end{array}$ & $\begin{array}{l}\text { Physical and Network } \\
\text { layer }\end{array}$ & $\begin{array}{l}\text { T-XLM specific protocol } \\
\text { TruFiX performs better than } \\
\text { RBSS(resource bound } \\
\text { security solution) based } \\
\text { protocols with regard to } \\
\text { security performance. }\end{array}$ & $\begin{array}{l}\text { Both SVM and MCDA are } \\
\text { being used to evaluate the } \\
\text { effectiveness and efficiency } \\
\text { of each routing estimation } \\
\text { technique. }\end{array}$ \\
\hline$[56]$ & $\begin{array}{l}\text { CLD Based security } \\
\text { Framework }\end{array}$ & $\begin{array}{l}\text { The Network layer, } \\
\text { MAC and Physical } \\
\text { layer }\end{array}$ & $\begin{array}{l}\text { CLBCSF( cross-layer based } \\
\text { comprehensive security } \\
\text { framework) is an appropriate } \\
\text { model used for the } \\
\text { hierarchical clustering. }\end{array}$ & $\begin{array}{l}\text { CLBCSF gives a new } \\
\text { direction towards protecting } \\
\text { the communication links and } \\
\text { extending the lifespan of the } \\
\text { whole network. }\end{array}$ \\
\hline$[57]$ & $\begin{array}{l}\text { Cross-layer resource } \\
\text { allocation technique }\end{array}$ & $\begin{array}{l}\text { Application layer, } \\
\text { MAC layer, and } \\
\text { Physical layer }\end{array}$ & $\begin{array}{l}\text { The images that are moving } \\
\text { across the network must be } \\
\text { protected. }\end{array}$ & --------------------------- \\
\hline$[58]$ & $\begin{array}{l}\text { EDES- based on a cross- } \\
\text { layer approach }\end{array}$ & $\begin{array}{l}\text { Application layer, } \\
\text { Network, and MAC } \\
\text { layer }\end{array}$ & $\begin{array}{l}\text { Defining the security level } \\
\text { for the various scenario can } \\
\text { improve energy efficiency } \\
\text { and QoS. }\end{array}$ & $\begin{array}{l}\text { Plan to extend the study to } \\
\text { dynamic MWSNs by using } \\
\text { mobility. }\end{array}$ \\
\hline
\end{tabular}




\subsection{Error Control}

An efficient cross-layer erasure coding technique in [59] determines the redundancy rate of erasure coding. It keeps trying to adapt the channel condition with the traffic load in the application layer. Another technique to detect redundancy in the wireless link layer is the hybrid FEC/ARQ method. Afterward, the objective function is proposed for FEC/ARQ approach. It controls the parameters through packet loss Information. At last, the UEP approach was used to improve the efficiency and consistency of the transmission of video packets. The result of the simulation verified the performance of the cross-layer error control method in contrast to other approaches with respect to different parameters like energy efficiency, PSNR, and delayedrestricted PSNR.

\subsection{Network Resource Management}

The authors in [63] represented a new cross-layer technique namely cross-layer collaborative communication (CL-CC). The sensor nodes must be adjusted to the changes in their environment to achieve successful network management. At any time, CL-CC uses temporal correlation to correctly estimate the node's sleeping time. It assists the node is transmitting data of higher quality and also reducing redundancy of data and energy usage. Spatial correlation is also used by sensor nodes to change their sensing activities. The simulation result indicates that the performance of CL-CC is better than the CC-MAC, LSWCC \& Anycast to improve network performance.

Table 7: CLD approaches for WSN by error control

\begin{tabular}{|c|c|c|c|c|}
\hline Reference Paper & CLD approach & $\begin{array}{l}\text { Layers contributed in CLD } \\
\text { approach }\end{array}$ & Result of CLD approach & Future scope \\
\hline$[59]$ & $\begin{array}{l}\text { Novel adaptive } \\
\text { cross-layer protocol } \\
\text { intended for error } \\
\text { control across } \\
\text { WMSN }\end{array}$ & $\begin{array}{l}\text { Application layer and Link } \\
\text { layer }\end{array}$ & $\begin{array}{l}\text { NAC offers improved performance } \\
\text { as a contrast to the other error control } \\
\text { methods in real-time multimedia } \\
\text { streaming across networks. }\end{array}$ & ------------------ \\
\hline$[60]$ & $\begin{array}{l}\text { CLD approach for } \\
\text { error control scheme } \\
\text { in 3-D UWSNs }\end{array}$ & $\begin{array}{l}\text { Network, MAC and Physical } \\
\text { layer }\end{array}$ & $\begin{array}{l}\text { HARQ-I and FEC block codes have } \\
\text { high error correction feature and a } \\
\text { small } \mathrm{n} / \mathrm{k} \text { ratio is the most } \\
\text { appropriate for error control } \\
\text { schemes. }\end{array}$ & $\begin{array}{l}\text { Initial tests with an } \\
\text { underwater } \\
\text { research platform, and } \\
\text { assessment and } \\
\text { comparison of results by } \\
\text { using Fountain Codes. }\end{array}$ \\
\hline$[61]$ & $\begin{array}{l}\text { CLD approach for } \\
\text { error control in } \\
\text { WMSNs }\end{array}$ & $\begin{array}{l}\text { Application layer, Transport } \\
\text { layer, and Physical layer }\end{array}$ & $\begin{array}{l}\text { FEC approach capable to deliver } \\
\text { strong bit error correction to solve } \\
\text { packet loss in multi-hop transfer. }\end{array}$ & ------------------ \\
\hline$[62]$ & $\begin{array}{l}\text { Cross-layer method } \\
\text { for error control } \\
\text { mechanism in WSN }\end{array}$ & $\begin{array}{l}\text { Network, MAC and Physical } \\
\text { layer }\end{array}$ & $\begin{array}{l}\text { Hybrid ARQ and FEC methods } \\
\text { significantly enhance error resilience } \\
\text { Communication in contrast to ARQ. }\end{array}$ & $\begin{array}{l}\text { FEC scheme can be used } \\
\text { in multimedia } \\
\text { applications. }\end{array}$ \\
\hline
\end{tabular}

Table 8: CLD approaches for WSN by Network Resource Management

\begin{tabular}{|c|l|l|l|l|}
\hline Reference Paper & CLD approach & $\begin{array}{l}\text { Layers contributed } \\
\text { in CLD approach }\end{array}$ & Result of CLD approach & Future scope \\
\hline$[63]$ & $\begin{array}{l}\text { Correlation among nodes to } \\
\text { improve the effectiveness of } \\
\text { the network by CLD } \\
\text { approach }\end{array}$ & MAC layer & $\begin{array}{l}\text { CL-CC determines the node's sleep } \\
\text { time to transfer high - quality } \\
\text { information while reducing data } \\
\text { redundancy and power } \\
\text { consumption. }\end{array}$ & $\begin{array}{l}\text { Aim to expand the } \\
\text { current work on } \\
\text { mobile WSN. }\end{array}$ \\
\hline$[64]$ & $\begin{array}{l}\text { CLD for network lifetime } \\
\text { optimization }\end{array}$ & $\begin{array}{l}\text { Network and MAC } \\
\text { layer }\end{array}$ & $\begin{array}{l}\text { Optimize the network life of WNSs } \\
\text { by evaluating the impact of both the } \\
\text { physical layer parameters and SPP. }\end{array}$ & --------------- \\
\hline
\end{tabular}




\begin{tabular}{|c|c|c|c|}
\hline Abbreviations & Description & Abbreviations & Description \\
\hline CLD & Cross-Layer Design & WMSNs & Wireless Multimedia Sensor Networks \\
\hline WSN & Wireless Sensor Networks & SUIT & $\begin{array}{l}\text { Sensor Fuzzy-based Image } \\
\text { Transmission }\end{array}$ \\
\hline DMF & Data Management Framework & LBRF & Load Balanced Reliable Forwarding \\
\hline CLF & Cross-Layer Framework & DLBS & Directional Load Balanced Spreading \\
\hline $\mathrm{CE}$ & Configuration Engine & RRA & $\begin{array}{l}\text { Radius and data generation Rate } \\
\text { Adjustment }\end{array}$ \\
\hline CLM & Cross-Layer Management & T-XLM & Trust-based Cross-Layer Framework \\
\hline QoS & Quality of Service & CLBCSF & $\begin{array}{l}\text { Cross-Layer Based Comprehensive } \\
\text { Security Framework }\end{array}$ \\
\hline LEACH & $\begin{array}{l}\text { Low-Energy Adaptive } \quad \text { Clustering } \\
\text { Hierarchy }\end{array}$ & SVM & Support Vector Machine \\
\hline PDR & Packet Delay Ratio & MCDA & Multi-Criteria Decision System \\
\hline BPSK & Binary Phase-Shift Keying & RBSS & Resource Bound Security Solution \\
\hline $\mathrm{CH}$ & Cluster Head & NAC & $\begin{array}{l}\text { New Adaptive Cross-layer Error Control } \\
\text { Protocol }\end{array}$ \\
\hline DEAP & Distributed-Environment-Aware Protocol & UEP & Unequal Error Protection \\
\hline EECP & Energy Efficient Cross-layer Protocol & ARQ & Automatic Repeat Request \\
\hline EAP-CMAC & $\begin{array}{l}\text { Energy-Aware-Physical-layer } \quad \text { Network } \\
\text { Coding Cooperative MAC }\end{array}$ & HARQ & Hybrid ARQ \\
\hline DRPC & $\begin{array}{l}\text { Distributed Routing Algorithm with } \\
\text { Transmission Power Control }\end{array}$ & FEC & Forward Error Correction \\
\hline DPC & Distributed Power Control & PSNR & Peak Signal-to-Noise Ratio \\
\hline WUSNs & Wireless Underground Sensor Networks & CL-CC & $\begin{array}{l}\text { Cross-Layer Collaborative } \\
\text { Communication }\end{array}$ \\
\hline IQOS & Improved Quality of Service & MAC & Media Access Control \\
\hline $\mathrm{XLCP}$ & Cross-Layer Communication Protocol & CC-MAC & Correlation-based Collaborative MAC \\
\hline WBANs & Wireless Body Area Networks & LSWCC & $\begin{array}{l}\text { Localised Slepian-Wolf Coding-based } \\
\text { Correlation approach }\end{array}$ \\
\hline
\end{tabular}

\section{Categorization of Recent Cross-Layer Design by different techniques}

Except for the classification based on the number of layers participate in the optimization. Another categorization for cross-layer design in WSN could be technique. I summarize the table 10 according to the recent work of CLD in the WSN. 
Table 10: Categorization of CLD by different techniques

\begin{tabular}{|c|c|c|c|c|c|c|}
\hline Author et. al./Year & $\begin{array}{l}\text { Energy } \\
\text { efficiency }\end{array}$ & $\begin{array}{l}\text { Reliable } \\
\text { communication }\end{array}$ & $\begin{array}{l}\text { Quality of } \\
\text { service }\end{array}$ & Security & $\begin{array}{l}\text { Error } \\
\text { correction }\end{array}$ & $\begin{array}{l}\text { Network } \\
\text { resource }\end{array}$ \\
\hline Zhang et al. (2018) & $\sqrt{ }$ & & & & & \\
\hline Babber et al. (2017) & $\sqrt{ }$ & & & & & \\
\hline Saini et al. (2017) & $\sqrt{ }$ & & $\sqrt{ }$ & & & \\
\hline Sarvi et al. (2017) & & & & & $\sqrt{ }$ & \\
\hline Umar et al. (2017) & & & & $\sqrt{ }$ & & \\
\hline Sadiq et al. (2017) & $\sqrt{ }$ & & & & & \\
\hline Singh et al. (2017) & $\sqrt{ }$ & & & & & \\
\hline Xenakis et al. (2016) & $\sqrt{ }$ & & & & & \\
\hline Ammar et al. (2016) & $\sqrt{ }$ & & & & & \\
\hline Yan et al. (2016) & $\sqrt{ }$ & & & & & \\
\hline Anbagi et al. (2016) & & & $\sqrt{ }$ & & & \\
\hline Ranga et al. (2013) & & $\sqrt{ }$ & & & & \\
\hline Das et al. (2015) & $\sqrt{ }$ & & & & & $\sqrt{ }$ \\
\hline Lin et al. (2015) & $\sqrt{ }$ & & & & & \\
\hline Fouzi et al. (2015) & $\sqrt{ }$ & & & & & \\
\hline Demir et al. (2014) & & & $\sqrt{ }$ & & & \\
\hline Gawdan et al. (2011) & & & & $\sqrt{ }$ & & \\
\hline
\end{tabular}

\section{Cross-Layer Design Challenges}

Although there are many advantages of implementing the cross-layer architecture, there are still some new challenges faced by the system. Some of them are discussed in table 11.

Table 11: Challenges of CLD

\begin{tabular}{|l|l|l|}
\hline Challenges of CLD & Main Reason & Possible Solution \\
\hline Coexistence problem in CLD[3] & $\begin{array}{l}\text { Each CLD has its individual standard for } \\
\text { the interaction among different layers. }\end{array}$ & $\begin{array}{l}\text { The coexistence of CLD is determined by } \\
\text { the standardization of interfaces. }\end{array}$ \\
\hline Signalling problem in CLD & $\begin{array}{l}\text { There is also no standardized format or } \\
\text { way of exchange of cross-layer } \\
\text { information in the wireless network. }\end{array}$ & $\begin{array}{l}\text { To make use of ICMP Messages and packet } \\
\text { headers to avoid implementing a signalling } \\
\text { protocol. }\end{array}$ \\
\hline $\begin{array}{l}\text { Extra workload induced through } \\
\text { cross-layer signalling }\end{array}$ & $\begin{array}{l}\text { It results in an additional burden while } \\
\text { sharing information among the nodes. }\end{array}$ & $\begin{array}{l}\text { The layered abstraction method and } \\
\text { distributed mechanism may be used for } \\
\text { reducing overhead. }\end{array}$ \\
\hline $\begin{array}{l}\text { The nonexistence of universal } \\
\text { CLD }\end{array}$ & $\begin{array}{l}\text { CLD for any particular application might } \\
\text { not be appropriate for any other } \\
\text { application. }\end{array}$ & $\begin{array}{l}\text { Universal CLD is unlikely to exist for all of } \\
\text { the purposes. }\end{array}$ \\
\hline $\begin{array}{l}\text { Destruction of layered } \\
\text { architecture[65] }\end{array}$ & $\begin{array}{l}\text { Cross-layer may disrupt the very well- } \\
\text { organized layered design into a } \\
\text { disorganized design. }\end{array}$ & $\begin{array}{l}\text { TCP/IP model is used to enhance the } \\
\text { features and performance of the layer } \\
\text { without destroying its layered design. }\end{array}$ \\
\hline
\end{tabular}




\section{Conclusion}

In this paper, we have presented the goals and significance of CLD and its implementation method in WSN. It demonstrates the several frameworks for cross-layer design within the WSN. We have discussed in detail various cross-layer optimization techniques for wireless sensor networks. To bring wireless sensor networks more secure, energy-efficient, and optimized, the different aspects of the cross-layer design approach have been discussed.

In this paper, we have put forward many such techniques that not only improve the overall interactions but also improve the Qualityof-service(QoS). Furthermore, the challenges of cross-layer design have been highlighted and identified their possible solutions. This could be a reason for the future improvement in cross-layer design to overcome existing work limitations.

\section{References}

[1]. A.S. Sadiq, T.Z. Almohammad, R.A.B.M. Khadri, A.A. Ahmed, J. Lloret, "An Energy-Efficient Cross-Layer approach for cloud wireless green communications," 2017 2nd International Conference on Fog and Mobile Edge Computing, FMEC 2017, 230-234, 2017, doi:10.1109/FMEC.2017.7946436.

[2]. Mahmoud Q, editor. Cognitive networks: towards self-aware networks. John Wiley \& Sons; 2007.

[3]. B. Fu, Y. Xiao, H.J. Deng, H. Zeng, "A survey of cross-layer designs in wireless networks," IEEE Communications Surveys and Tutorials, 16(1), 110-126, 2014, doi:10.1109/SURV.2013.081313.00231.

[4]. Jurdak R. Wireless ad hoc and sensor networks: A cross-layer design perspective. Springer Science \& Business Media; 2007.

[5]. F. Wang, "A Survey of Recent Cross-layer Designs in Sensor Networks," (December), 2016.

[6]. Z. Hamid, F.B. Hussain, "QoS in wireless multimedia sensor networks: A layered and cross-layered approach," Wireless Personal Communications, 75(1), 729-757, 2014, doi:10.1007/s11277-013-1389-0.

[7]. K. Babber, R. Randhawa, "A Cross-Layer Optimization Framework for Energy Efficiency in Wireless Sensor Networks," Wireless Sensor Network, 09(06), 189-203, 2017, doi:10.4236/wsn.2017.96011.

[8]. S. Networks, "Cross-layer design and optimisation for wireless sensor networks Weilian Su* and Tat L. Lim," 6(1), 2009.

[9]. L. Song, "Cross Layer Design in Wireless Sensor Networks: A Systematic Approach," (December), 2008.

[10]. D. Wu, S. Ci, H. Luo, H.F. Guo, "A theoretical framework for interaction measure and sensitivity analysis in cross-layer design," ACM Transactions on Modeling and Computer Simulation, 21(1), 2010, doi:10.1145/1870085.1870091.

[11]. Devi, C. Dhivya, and K. Vidya. "A survey on cross-layer design approach for secure wireless sensor networks." In International Conference on Innovative Computing and Communications, pp. 43-59. Springer, Singapore, 2019.

[12]. R. Ranjan, S. Varma, "Challenges and Implementation on Cross Layer Design for Wireless Sensor Networks," Wireless Personal Communications, 86(2), 1037-1060, 2016, doi:10.1007/s11277-015-2972-3.

[13]. V. Srivastava, M. Motani, "The road ahead for cross-layer design," 2nd International Conference on Broadband Networks, BROADNETS 2005, 2005, 593-602, 2005, doi:10.1109/ICBN.2005.1589660.

[14]. O. Karaca, R. Sokullu, "Comparative study of cross layer frameworks for wireless sensor networks," Proceedings of the 2009 1st International Conference on Wireless Communication, Vehicular Technology, Information Theory and Aerospace and Electronic Systems Technology, Wireless VITAE 2009, (June 2009), 896-900, 2009, doi:10.1109/WIRELESSVITAE.2009.5172568.

[15]. P.J. Marron, A. Lachenmann, D. Minder, J. Hähner, R. Sauter, K. Rothermel, "TinyCubus: A flexible and adaptive framework for sensor networks," Proceedings of the Second European Workshop on Wireless Sensor Networks, EWSN 2005, 2005, 278-289, 2005, doi:10.1109/EWSN.2005.1462020.
[16]. A.M. Safwat, "A novel framework for cross-layer design in wireless ad hoc and sensor networks," GLOBECOM - IEEE Global Telecommunications Conference, 130-135, 2004, doi:10.1109/glocomw.2004.1417561.

[17]. N. Zhao, L. Sun, "Research on cross-layer frameworks design in wireless sensor networks," Third International Conference on Wireless and Mobile Communications 2007, ICWMC '07, 5-7, 2007, doi:10.1109/ICWMC.2007.75.

[18]. M.S. Sumalatha, V. Nandalal, "An intelligent cross layer security based fuzzy trust calculation mechanism (CLS-FTCM) for securing wireless sensor network (WSN)," Journal of Ambient Intelligence and Humanized Computing, (0123456789), 2020, doi:10.1007/s12652-020-01834-1.

[19]. Saini, Rakesh Kumar, and Sandip Vijay Ritika. "A Survey on Cross Layer Design implementation in Wireless Sensor Network." Int J Adv Inf Sci Technol IJAIST 5 (2016): 101-107.

[20]. Sarkar, Subir Kumar, Tiptur Gangaraju Basavaraju, and C. Puttamadappa. Ad hoc mobile wireless networks: principles, protocols and applications. CRC Press, 2007.

[21]. D. Lin, S. Li, "TCLA: A triangular cross-layer architecture for wireless sensor networks," 4th International Conference on Frontier of Computer Science and Technology, FCST 2009, 272-278, 2009, doi:10.1109/FCST.2009.50.

[22]. H.A. Khattak, Z. Ameer, I.U. Din, M.K. Khan, "Cross-layer design and optimization techniques in wireless multimedia sensor networks for smart cities," Computer Science and Information Systems, 16(1), 1-17, 2019, doi:10.2298/CSIS181115004K.

[23]. P. Sarwesh, N.S. V. Shet, K. Chandrasekaran, "ETRT - Cross layer model for optimizing transmission range of nodes in low power wireless networks - An Internet of Things Perspective," Physical Communication, 29, 307-318, 2018, doi:10.1016/j.phycom.2018.06.005.

[24]. R. Singh, A.K. Verma, "Efficient image transfer over WSN using cross layer architecture," Optik, 130, 499-504, 2017, doi:10.1016/j.ijleo.2016.10.143.

[25]. L.D.P. Mendes, J.J.P.C. Rodrigues, "A survey on cross-layer solutions for wireless sensor networks," Journal of Network and Computer Applications, 34(2), 523-534, 2011, doi:10.1016/j.jnca.2010.11.009.

[26]. A. Ben Ammar, A. Dziri, M. Terre, H. Youssef, "Multi-hop LEACH based cross-layer design for large scale wireless sensor networks," 2016 International Wireless Communications and Mobile Computing Conference, IWCMC 2016, 763-768, 2016, doi:10.1109/IWCMC.2016.7577153.

[27]. W. Zhang, X. Wei, G. Han, "An Energy-Efficient Ring Cross-Layer Optimization Algorithm for Wireless Sensor Networks," IEEE Access, 6, 16588-16598, 2018, doi:10.1109/ACCESS.2018.2809663.

[28]. F. Bouabdallah, N. Bouabdallah, R. Boutaba, "Cross-layer design for energy conservation in wireless sensor networks," IEEE International Conference on Communications, 0-5, 2009, doi:10.1109/ICC.2009.5198872.

[29]. N. Chilamkurti, S. Zeadally, A. Vasilakos, V. Sharma, "Cross-layer support for energy efficient routing in wireless sensor networks," Journal of Sensors, 2009, 2009, doi:10.1155/2009/134165.

[30]. T. Jaradat, D. Benhaddou, M. Balakrishnan, A. Al-Fuqaha, "Energy efficient cross-layer routing protocol in Wireless Sensor Networks based on fuzzy logic," 2013 9th International Wireless Communications and Mobile Computing Conference, IWCMC 2013, 177-182, 2013, doi:10.1109/IWCMC.2013.6583555.

[31]. M. Luca, M. Vincenzo, L. Patrono, "HEC-MAC: A hybrid energy-aware cross-layer MAC protocol for wireless sensor networks," International Journal of Distributed Sensor Networks, 11(4), 2015, doi: $10.1155 / 2015 / 536794$.

[32]. S. Liu, Y. Bai, M. Sha, Q. Deng, D. Qian, "CLEEP : A Novel Cross-Layer Energy-Efficient Protocol for Wireless Sensor Networks," 2-5, 2008.

[33]. F. Semchedine, W. Oukachbi, N. Zaichi, L. Bouallouche-Medjkoune, "EECP: A New Cross-layer Protocol for Routing in Wireless Sensor Networks," Procedia Computer Science, 73(Awict), 336-341, 2015, doi:10.1016/j.procs.2015.12.001.

[34]. R. Singh, A.K. Verma, "Energy efficient cross layer based adaptive threshold routing protocol for WSN," AEU - International Journal of Electronics and Communications, 72, 166-173, 2017, doi:10.1016/j.aeue.2016.12.001.

[35]. A. Xenakis, F. Foukalas, G. Stamoulis, "Cross-layer energy-aware topology control through Simulated Annealing for WSNs," Computers and Electrical Engineering, 56(March), 576-590, 2016, doi:10.1016/j.compeleceng.2016.02.015

[36]. M. Sami, N.K. Noordin, F. Hashim, S. Subramaniam, A. AkbariMoghanjoughi, “An Energy-Aware Cross-Layer Cooperative MAC Protocol for Wireless Ad Hoc Networks," Journal of Network and Computer Applications, 58, 227-240, 2015, doi:10.1016/j.jnca.2015.08.009.

[37]. Q.V. Pham, H.L. To, W.J. Hwang, "A multi-timescale cross-layer approach 753 
for wireless ad hoc networks," Computer Networks, 91, 471-482, 2015, doi:10.1016/j.comnet.2015.08.007.

[38]. X. Wang, Q. Sun, Y. Yang, "A cross-layer mobility support protocol for wireless sensor networks," Computers and Electrical Engineering, 48, 330342, 2015, doi:10.1016/j.compeleceng.2015.06.017

[39]. S.R. Chudasama, S.D. Trapasiya, "Packet size optimization in wireless sensor network using cross-layer design approach," Proceedings of the 2014 International Conference on Advances in Computing, Communications and Informatics, ICACCI 2014, 2506-2511, 2014, doi:10.1109/ICACCI.2014.6968357.

[40]. S.C. Lin, I.F. Akyildiz, P. Wang, Z. Sun, "Distributed Cross-Layer Protocol Design for Magnetic Induction Communication in Wireless Underground Sensor Networks," IEEE Transactions on Wireless Communications, 14(7), 4006-4019, 2015, doi:10.1109/TWC.2015.2415812.

[41]. Y. Chen, L. Gao, Y. Xing, W. Yi, "Cross-Layer Design for Energy-Efficient Reliable Routing in Wireless Sensor Networks," Proceedings - 11th International Conference on Mobile Ad-Hoc and Sensor Networks, MSN 2015, 31-36, 2016, doi:10.1109/MSN.2015.44.

[42]. B. Jain, G.S. Brar, J. Malhotra, "A Survey on Design and Development of Energy Efficient Cross Layer Approaches in Wireless Sensor Networks," 2(4), 273-279, 2014.

[43]. I. Al-Anbagi, M. Erol-Kantarci, H.T. Mouftah, "A survey on cross-layer quality-of-service approaches in WSNs for delay and reliability-aware applications," IEEE Communications Surveys and Tutorials, 18(1), 525-552, 2016, doi:10.1109/COMST.2014.2363950.

[44]. R.K. Saini, . R., "IQOS: A Cross Layer Design Approach for Improve Quality of Service in Wireless Sensor Networks," International Journal of Advanced Science and Technology, 103, 1-8, 2017, doi:10.14257/ijast.2017.103.01.

[45]. A.K. Demir, H.E. Demiray, S. Baydere, "QoSMOS: Cross-layer QoS architecture for wireless multimedia sensor networks," Wireless Networks, 20(4), 655-670, 2014, doi:10.1007/s11276-013-0628-3.

[46]. K. Takabayashi, H. Tanaka, C. Sugimoto, K. Sakakibara, R. Kohno, "CrossLayer Design and Performance Analysis of Quality of Service Control Scheme for Wireless Body Area Networks," IEEE Access, 5, 22462-22470, 2017, doi:10.1109/ACCESS.2017.2762078.

[47]. G.A. Shah, W. Liang, O.B. Akan, "Cross-layer framework for QoS support in wireless multimedia sensor networks," IEEE Transactions on Multimedia, 14(5), 1442-1455, 2012, doi:10.1109/TMM.2012.2196510.

[48]. I.T. Almalkawi, M. Guerrero Zapata, J.N. Al-Karaki, “A cross-layer-based clustered multipath routing with QoS-aware scheduling for wireless multimedia sensor networks," International Journal of Distributed Sensor Networks, 2012(2), 2012, doi:10.1155/2012/392515.

[49]. V. Ranga, R. Gupta, "Cross-Layered Framework in WSNs to Enhance Transmission Reliability," 2013.

[50]. C. Sonmez, S. Isik, M.Y. Donmez, O.D. Incel, C. Ersoy, "SUIT: A cross layer image transport protocol with fuzzy logic based congestion control for wireless multimedia sensor networks," 2012 5th International Conference on New Technologies, Mobility and Security - Proceedings of NTMS 2012 Conference and Workshops, (May), 2012, doi:10.1109/NTMS.2012.6208750.
[51]. S. Pudlewski, T. Melodia, "DMRC: Distortion-minimizing rate control for wireless multimedia sensor networks," 2009 IEEE 6th International Conference on Mobile Adhoc and Sensor Systems, MASS '09, 563-572, 2009, doi:10.1109/MOBHOC.2009.5336954.

[52]. S. Isik, M.Y. Donmez, C. Ersoy, "Cross layer load balanced forwarding schemes for video sensor networks," Ad Hoc Networks, 9(3), 265-284, 2011, doi:10.1016/j.adhoc.2010.07.002.

[53]. L. Shu, M. Hauswirth, Y. Zhang, J. Ma, G. Min, Y. Wang, "Cross layer optimization for data gathering in wireless multimedia sensor networks within expected network lifetime," Journal of Universal Computer Science, 16(10), 1343-1367, 2010, doi:10.3217/jucs-016-10-1343.

[54]. I.A. Umar, Z.M. Hanapi, A. Sali, Z.A. Zulkarnain, "TruFiX: A Configurable Trust-Based Cross-Layer Protocol for Wireless Sensor Networks," IEEE Access, 5, 2550-2562, 2017, doi:10.1109/ACCESS.2017.2672827.

[55]. N.K. Goud, S.G. Assistant, I.T. Depart, "An Efficient Trust Based Cross Layer Protocol for Wireless Sensor Networks," 118(20), 343-357, 2018.

[56]. I.S. Gawdan, C.O. Chow, T.A. Zia, Q.I. Gawdan, "Cross-layer based security solutions for wireless sensor networks," International Journal of Physical Sciences, 6(17), 4245-4254, 2011, doi:10.5897/IJPS11.542.

[57]. W. Wang, D. Peng, H. Wang, H. Sharif, "A cross layer resource allocation scheme for secure image delivery in wireless sensor networks," IWCMC 2007: Proceedings of the 2007 International Wireless Communications and Mobile Computing Conference, 152-157, 2007 , doi: $10.1145 / 1280940.1280973$.

[58]. A. Rachedi, L. Kaddar, A. Mehaoua, "EDES - Efficient dynamic selective encryption framework to secure multimedia traffic in Wireless Sensor Networks," IEEE International Conference on Communications, 1026-1030, 2012, doi:10.1109/ICC.2012.6364221

[59]. B. Sarvi, H.R. Rabiee, K. Mizanian, "An adaptive cross-layer error control protocol for wireless multimedia sensor networks," Ad Hoc Networks, 56, 173-185, 2017, doi:10.1016/j.adhoc.2016.12.008.

[60]. M.C. Domingo, M.C. Vuran, "Cross-layer analysis of error control in underwater wireless sensor networks," Computer Communications, 35(17), 2162-2172, 2012, doi:10.1016/j.comcom.2012.07.010.

[61]. Y. Yang, Y. Chen, W. Yi, "Cross-layer forward error control for reliable transfer in wireless multimedia sensor networks," 2010 7th IEEE Consumer Communications and Networking Conference, CCNC 2010, 0-1, 2010, doi:10.1109/CCNC.2010.5421716.

[62]. M.C. Vuran, I.F. Akyildiz, "Error control in wireless sensor networks: A cross layer analysis," IEEE/ACM Transactions on Networking, 17(4), 11861199, 2009, doi:10.1109/TNET.2008.2009971.

[63]. S.N. Das, S. Misra, "Correlation-aware cross-layer design for network management of wireless sensor networks," IET Wireless Sensor Systems, 5(6), 263-270, 2015, doi:10.1049/iet-wss.2014.0110.

[64]. H. Yetgin, K.T.K. Cheung, M. El-Hajjar, L. Hanzo, "A Survey of Network Lifetime Maximization Techniques in Wireless Sensor Networks," IEEE Communications Surveys and Tutorials, 19(2), 828-854, 2017, doi:10.1109/COMST.2017.2650979.

[65]. D.K. Sah, T. Amgoth, "Parametric survey on cross-layer designs for wireless sensor networks," Computer Science Review, 27, 112-134, 2018, doi:10.1016/j.cosrev.2017.12.002. 